\title{
Pengembangan Sistem Informasi Pemantauan Kuis dan Tugas pada Learning Management Systems Moodle
}

\author{
Raka Firmansyah $^{* 1}$, Muhammad Syaiful Aliim², Eko Murdyantoro Atmojo ${ }^{3}$ \\ ${ }^{123}$ Program Studi Teknik Elektro, Fakultas Teknik, Universitas Jenderal Soedirman, Indonesia \\ Email: ${ }^{1}$ raka.firmansyah@mhs.unsoed.ac.id, ${ }^{2}$ muhammad.syaiful.aliim@unsoed.ac.id, \\ ${ }^{3}$ eko.atmojo@unsoed.ac.id
}

\begin{abstract}
Abstrak
Perkembangan sistem informasi dewasa ini telah merambah ke berbagai elemen kehidupan, salah satunya adalah pada bidang akademik. Salah satu yang sangat populer adalah sistem manajemen pembelajaran online, dan contoh dari perangkat lunak yang digunakan adalah Moodle. Moodle merupakan platform pembelajaran yang dirancang untuk memberi para pendidik, administrator, dan pelajar dengan satu sistem yang kuat, aman, dan terintegrasi untuk menciptakan lingkungan belajar yang dipersonalisasi. eLDirU merupakan platform pembelajaran berbasis moodle. eLDirU memiliki banyak fitur seperti mengakses course atau matakuliah, melakukan pengumpulan tugas, serta mengerjakan kuis yang diberikan oleh dosen. Dengan banyaknya jumlah kelas dan Dengan banyaknyan kuis serta tugas yang diupload pada eLDirU, menimbulkan permasalahan bagi admin untuk mengelola kuis dan tugas secara manual. yang perlu adanya suatu sistem monitoring agar user maupun admin dapat dengan mudah memfilter kuis dan tugas yang sudah diupload pada eLDirU. Dengan dikembangkannya aplikasi sistem informasi monitoring kuis dan tugas, masalah filterisasi kuis dan tugas pada eLDirU dapat teratasi sekaligus membuat kuis dan tugas mampu dikelola dengan baik oleh admin tanpa perlu melakukan pengecekan disetiap masing-masing kelas.
\end{abstract}

Kata kunci: eLDirU, moodle, sistem informasi, sistem monitoring

\section{Development of Quiz and Task Monitoring Information System in Moodle Learning Management Systems}

\begin{abstract}
The development of information systems today has penetrated various elements of life, one of which is in the academic field. One very popular is the online learning management system, and an example of the software used is Moodle. Moodle is a learning platform designed to provide educators, administrators and students with a robust, secure and integrated system for creating a personalized learning environment. eLDirU is a moodle-based learning platform. eLDirU has many features such as accessing courses or courses, collecting assignments, and taking quizzes given by lecturers. With the large number of classes and the large number of quizzes and assignments uploaded to eLDirU, it creates problems for admins to manage quizzes and assignments manually. which requires a monitoring system so that users and admins can easily filter quizzes and assignments that have been uploaded to eLDirU. With the development of a quiz and assignment monitoring information system application, the problem of filtering quizzes and assignments in eLDirU can be resolved while making quizzes and assignments manageable by the admin without the need to check each class.
\end{abstract}

Keywords: eLDirU, information system, moodle, monitoring system

\section{PENDAHULUAN}

Perkembangan sistem informasi saat ini telah menyebar ke berbagai elemen kehidupan, salah satunya adalah pada bidang akademik. Sudah sejak lama sistem informasi dikembangkan untuk menunjang kehidupan di bidang akademik. Hal ini menimbulkan banyaknya inovasi-inovasi yang muncul dan berkembang secara terus menerus pada bidang akademik.

Dari banyaknya perkembangan yang terjadi, salah satunya adalah terciptanya sistem informasi yang dapat mengelola dan menunjang terjadi nya relasi antara berbagai unsur-unsur akademik seperti guru, murid, administrator, dan aktor lain yang terlibat. Moodle merupakan (LMS) Learning Management System atau platform pembelajaran yang dirancang untuk memberi para pendidik, administrator, dan pelajar dengan satu sistem yang 
kuat, aman, dan terintegrasi untuk menciptakan lingkungan belajar yang dipersonalisasi kemudian moodle juga software yang mendukung model pembelajaran mata kuliah secara online dan memiliki kelengkapan modul dan fasilitas serta mudah diterapkan[1].

eLDirU merupakan platform pembelajaran berbasis Moodle milik Universitas Jenderal Soedirman. eLDirU dikembangkan oleh lembaga LP3M untuk memenuhi kebutuhan pembelajaran secara daring dimana sebagai implementasi dari tugas LP3M dimana merencanakan, melaksanakan, mengkoordinasikan, memantau dan mengevaluasi kegiatan pengembangan pembelajaran dan penjaminan mutu[2]. eLDirU memiliki banyak fitur yang dapat digunakan, beberapa fitur yang diberikan seperti mengakses course atau mata kuliah, melakukan pengumpulan tugas, serta mengerjakan kuis yang diberikan oleh dosen. Seperti Didik Budi lakukan menggunakan eLDirU sebagai alternatif penilaian prestasi belajar mahasiswa di mata kuliah pembelajaran senam[3].

Dengan meningkatnya penggunaan eLDirU berbanding lurus dengan banyaknya jumlah kuis serta tugas yang diupload pada eLDirU. Anistyasari telah melakukan penelitian untuk membandingkan LMS berbasis Moodle dengan Dokeos dimana jumlah jenis pertanyaan yang dimiliki mencapai 16 jenis pertanyaan standar dan 50 jenis pertanyaan dari pihak ketiga[4]. admin eLDirU mengalami kesulitan dalam mengelola kuis dan tugas yang sudah diupload oleh para dosen terutama pada saat kegiatan UTS dan UAS. Karena admin perlu mengecek kuis dan tugas berdasarkan mata kuliah pada menu pencarian pada Moodle. Dengan jumlah course yang cukup banyak tentu tidak akan efisien jika informasi kuis dan tugas ditampilkan dalam satu tampilan. Untuk melakukan POC (Proof of Concept) pengembangan sistem informasi manajemen kuis dan tugas dengan menarik data secara langsung dari database moodle. Penelitian yang dilakukan oleh Zacarias menunjukan untuk membangun report perlu mengambil data langsung kedatabase moodle namun dengan banyak data maka akan memerlukan pemrosesan data yang cukup berat dan pembuatan laporan secara kustom akan memakan biaya[5].

Untuk mengatasi permasalahan ini maka dikembangkan sebuah sistem informasi manajemen kuis dan tugas untuk mengelola kuis dan tugas yang sudah dibuat didalam LMS eLDirU. Pembuatan sistem informasi dilakukan karena sudah banyak digunakan untuk kasus-kasus yang membutuhkan pengelolaan atau manajemen terhadap informasi. Seperti contohnya yang dilakukan Rahayuning membangun sistem informasi industri kecil untuk pemerintahan kabupaten boyolali berbasis website[6]. Kemudian penelitian yang dilakukan Gultom dengan membangun sistem informasi penjualan material bangunan pada toko bangunan[7].

\section{METODE PENELITIAN}

Untuk mengatasi permasalahan yang terjadi pada LMS Moodle milik Universitas Jenderal Soedirman disaat terjadi kegiatan UTS dan UAS dimana kuis dan tugas tidak terkelola dengan baik. Metode penelitian digambarkan sebagai diagram alir seperti Gambar 1 berikut.

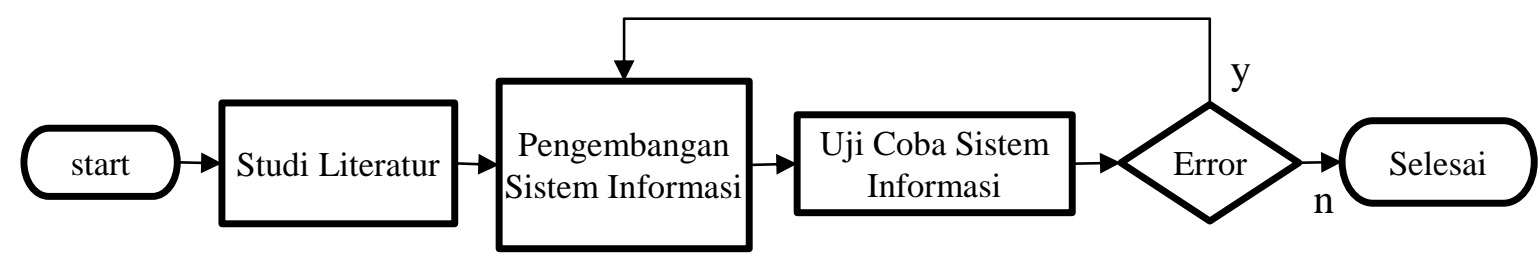

Gambar 1. Metode Penelitian

Penelitian dilakukan dengan melalui tiga tahapan yang pertama Studi Literatur, Pengembangan Sistem Informasi dan Uji Coba Sistem Informasi. Penjelasaan masing-masing tahapan dijelaskan sebagai berikut:

\subsection{Studi Literatur}

Tahapan ini dimulai dengan memahami struktur database LMS Moodle dengan mempelajari dokumentasi melalui halaman website Moodle. Eksplorasi posisi tabel yang merepresentasikan kuis dan tugas sehingga kemudian dapat membangun query untuk dapat mengakses informasi dari dalam tabel pada database moodle secara langsung. Studi literatur juga dilakukan untuk memahami penggunaan phpMyAdmin (halaman utama phpMyAdmin tampak pada Gambar 2 dan bahasa pemrograman PHP untuk persiapan membangun sistem informasi pada tahap selanjutnya.

\subsection{Pengembangan Sistem Informasi}

Tahap ini dilakukan untuk membuat GUI (Graphical User Interface) untuk menampilkan informasi kuis dan tugas yang akan ditarik langsung dari database Moodle. Pengembangan dilakukan dengan menggunakan cPanel 
dan PhpMyAdmin dengan menggunakan bahasa pemrograman php sehingga berbasis web. Tidak hanya membuat tampilan hasil query dari database namun juga membuat filter dalam pengambilan data.

\subsection{Uji Coba Sistem Informasi}

Tahap ini dilakukan untuk melakukan uji coba terhadap sistem informasi yang sudah dikembangkan pada tahap sebelumnya. Tahap ini memastikan output yang ditampilkan sesuai dengan informasi yang ditarik dari database dan informasi kuis dan tugas dapat dipahami oleh admin.

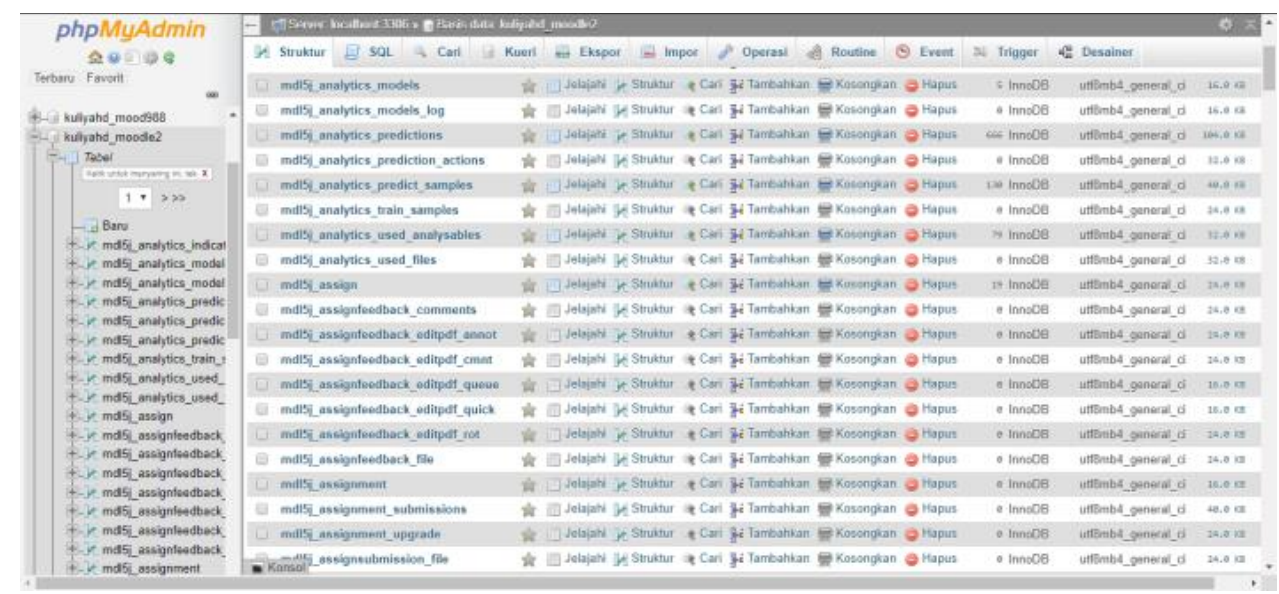

Gambar 2 . Halaman phpMyAdmin

\section{HASIL DAN PEMBAHASAN}

Sistem informasi monitoring kuis dan tugas memiliki dua layar. Layar pertama menampilkan kuis dan layar kedua menampilkan tugas. Tombol akses untuk masing-masing menu berada paling atas dan berupa tab. Pada menu pertama pencarian kuis terdapat dua filter yang pertama berdasarkan nama dan yang kedua berdasarkan waktu. Untuk menampilkan informasi kuis maka data ditampilkan dalam bentuk tabel dengan kolom yang terdiri dari course ID, course full name, quiz name, total users, date open, time open, date close, dan time close. Untuk tampilan dari menu pencarian kuis dapat dilihat pada Gambar 3 berikut.

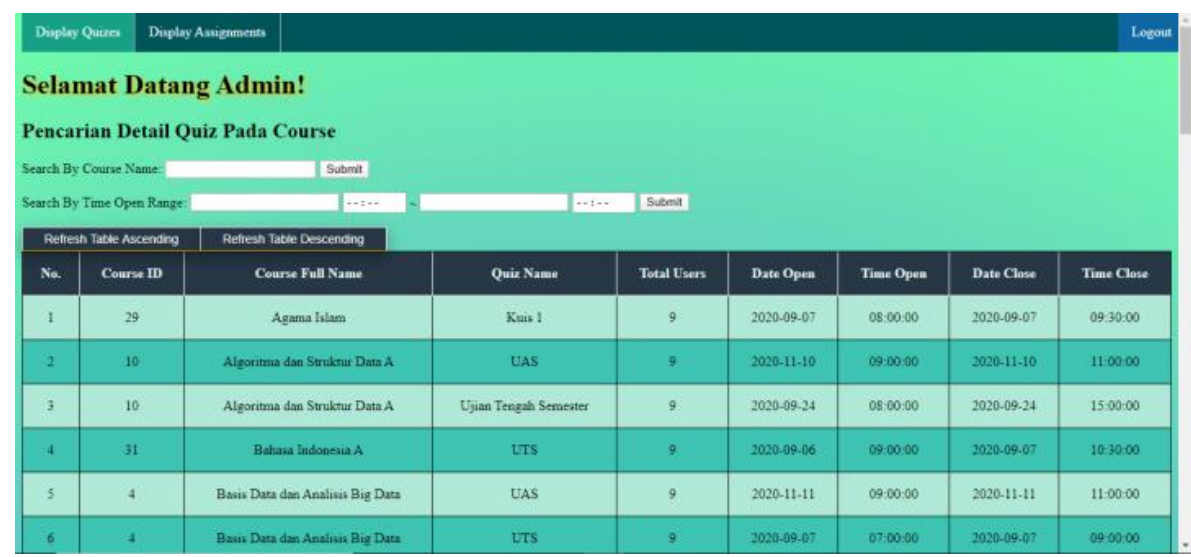

Gambar 3. Halaman Pencarian Kuis/Quiz

Untuk mendapatkan informasi kuis berdasarkan nama mata kuliah atau course name, maka pengguna cukup menginputkan nama mata kuliah di kolom course name kemudian menekan submit. Kemudian tabel akan menampilkan semua kuis yang dimiliki oleh mata kuliah yang sudah diinput sebelumnya seperti pada Gambar 4 .

Kemudian untuk menggunakan filter waktu arahkan kursor pada field open range kemudian akan muncul pop up berupa kalender yang dapat dipilih tahun, bulan dan tanggalnya sesuai dengan kebutuhan admin. Kemudian menginputkan jam dan menit pada kolom berikut nya. Pencarian kuis dengan waktu bisa dilakukan dengan waktu sesudah, sebelum, dan dalam range waktu tertentu. Kemudian diakhiri dengan menekan tombol submit seperti 
pada Gambar 5. Hasil perncarian kuis akan ditampilkan pada tabel sesuai dengan waktu yang diinput pada kolom seperti pada Gambar 6.

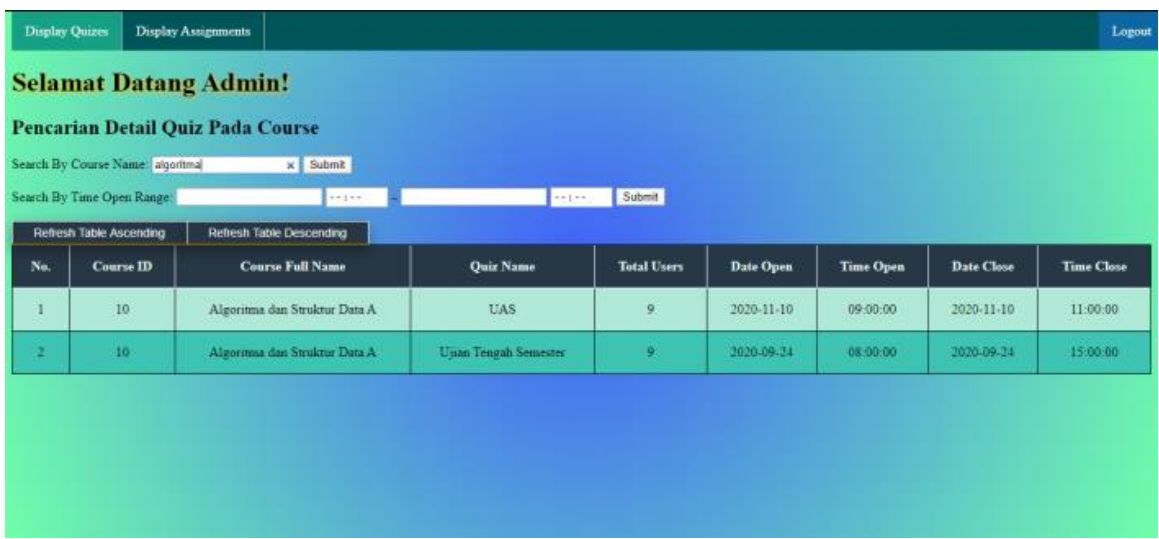

Gambar 4. Filter Course Name pencarian kuis

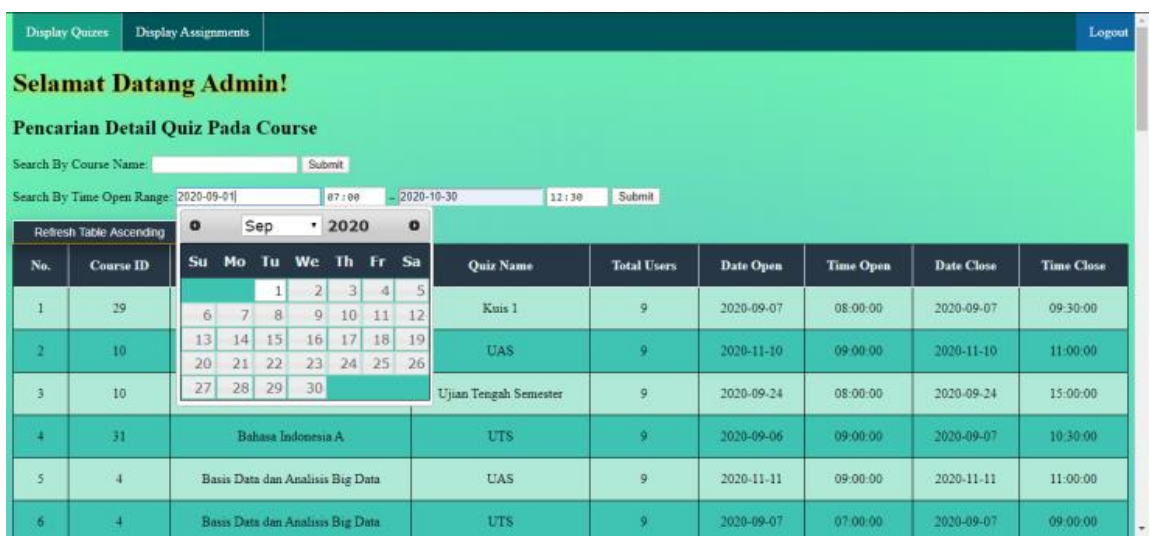

Gambar 5. Filter waktu pencarian kuis

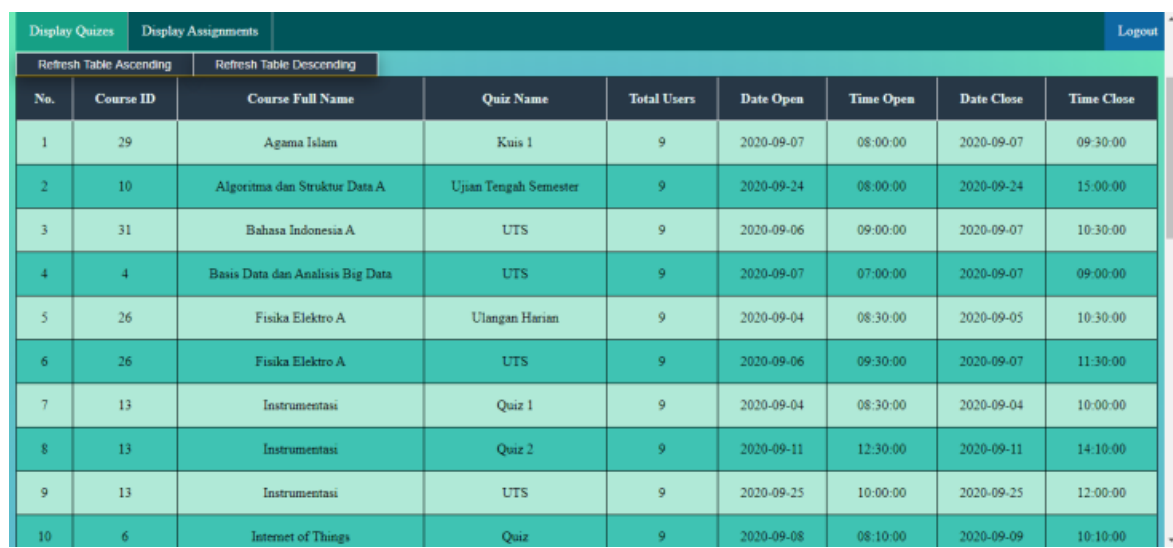

Gambar 6. Hasil pencarian kuis dengan filter waktu

Tampilan pada menu pencarian tugas juga sama dengan pencarian kuis. Memiliki dua filter dan satu tabel untuk menampilkan informasi tugas. Filter terdiri dari filter nama course dan waktu. Gambar 7 berikut adalah tampilan dari menu pencarian tugas. Untuk melakukan pencarian berdasarkan Course Name (Nama Mata Kuliah), cukup mengetikan nama mata kuliah pada kolom course name yang ingin ditampilkan datanya kemudian tekan tombol submit. Maka secara otomatis informasi tugas akan ditampilkan didalam tabel. Berikut adalah contoh pencarian dengan kata kunci berupa nama course.

Bila ingin melakukan pencarian berdasarkan waktu cukup meletakan kursor pada field open range kemudian akan otomatis muncul pop up yang berisikan kalender untuk menginputkan waktu. Variabel waktu yang diinputkan 
akan otomatis mengisi pada field dengan format "yyyy-mm-dd" pada kolom tanggal dan "hh:mm" pada field jam. Pencarian bisa dilakukan dengan tiga tipe mencari tugas dengan waktu setelah open range, sebelum waktu close range, dan diantara open range dan close range. Hasilnya dapat dilihat pada Gambar 8, Gambar 9 dan Gambar 10

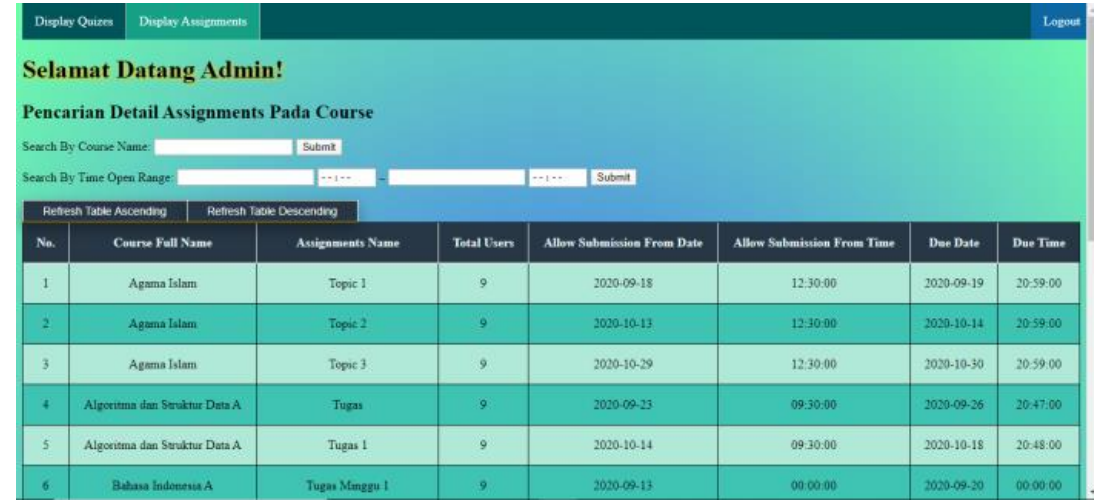

Gambar 7. Halaman Pencarian Tugas/Assignment

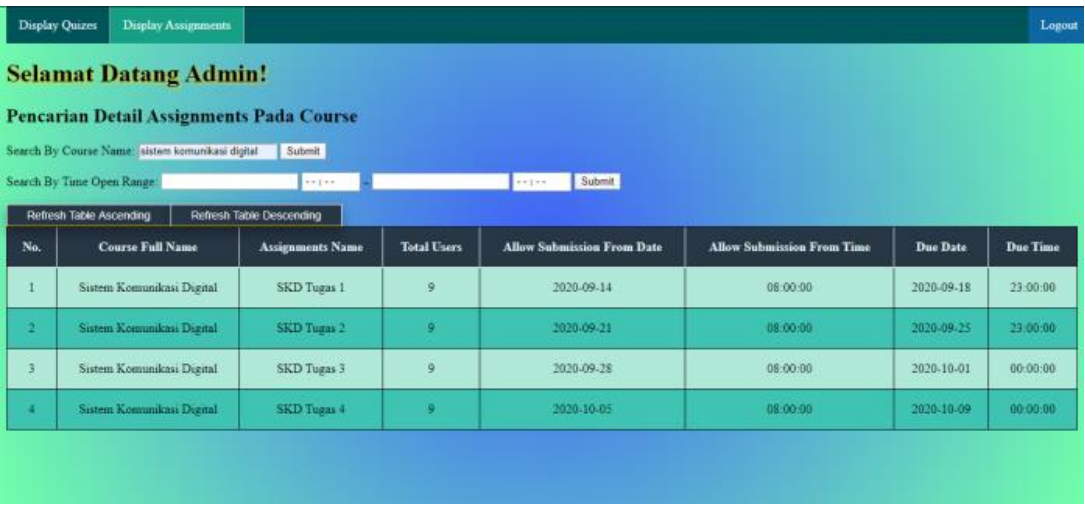

Gambar 8. Hasil Pencarian Tugas dengan filter Course Name

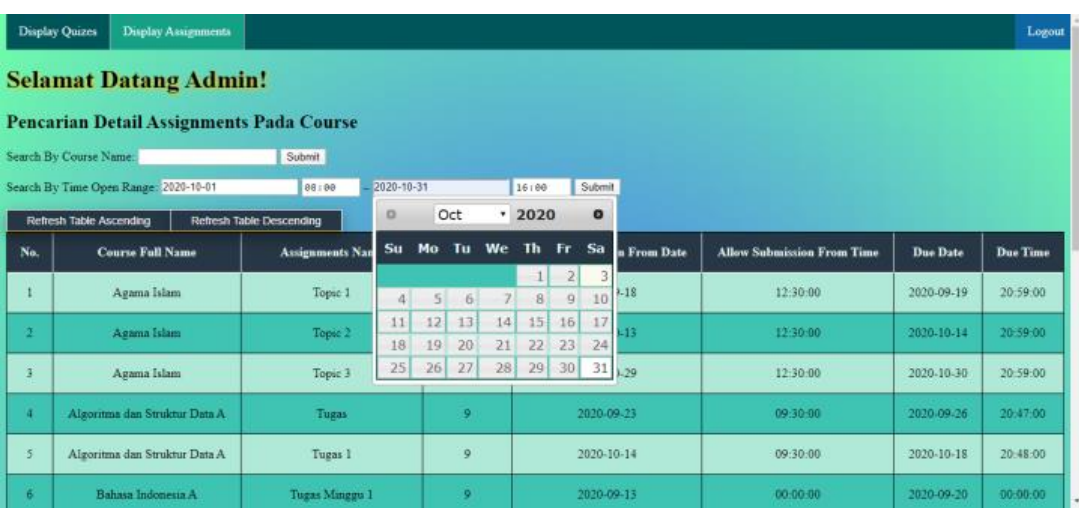

Gambar 9. Filter waktu pencarian tugas 


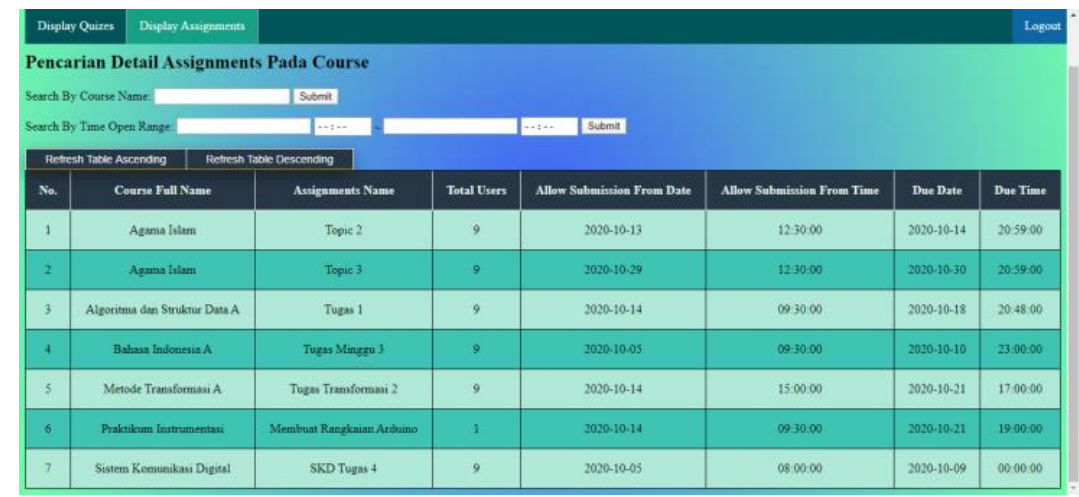

Gambar 10. Hasil pencarian tugas dengan filter waktu

Sistem informasi dibagi menjadi dua menu yaitu menu untuk menari kuis dengan dua kata kunci yaitu nama course atau mata kuliah dan tanggal. Untuk fungsi pencarian tanggal bisa dilakukan dengan mengetikan waktu mulai, waktu akhir, dan range waktu. Dengan menginputkan nama course maka akan menampilkan kuis dan tugas dari mata kuliah tersebut semua tanpa filter waktu. Jika filter waktu juga diisi maka hasil data akan menyesuiakan.

\section{KESIMPULAN}

Berdasarkan hasil pengembangan sistem informasi monitoring kuis dan tugas dari LMS Moodle maka didapat kesimpulan bahwa sistem informasi monitoring kuis dan tugas dari LMS Moodle eLDirU memudahkan admin dalam mengelola kuis dan tugas yang telah diupoad oleh dosen terutama dalam kondisi UTS dan UAS. Dimana admin tidak perlu melakukan pengecekan setiap mata kuliah atau course satu persatu. Karena daftar kuis dan tugas ditampilkan didalam satu aplikasi dan dalam bentuk tabel. Dengan dilengkapi fungsi filter validasi kuis dan tugas bisa dicari dengan mudah.

\section{DAFTAR PUSTAKA}

[1] A. Ambarita, "IMPLEMENTASI SISTEM E-LEARNING MENGGUNAKAN SOFTWARE MOODLE PADA POLITEKNIK SAINS DAN TEKNOLOGI WIRATAMA MALUKU UTARA,” IJIS - Indonesian Journal On Information System, vol. 1, no. 2, 2017, doi: 10.36549/ijis.v1i2.17.

[2] L. UNSOED, "Sejarah LP3M Universitas Jenderal Soedirman," lp3m.unsoed.ac.id. http://lp3m.unsoed.ac.id/menu/sejarah (accessed Sep. 24, 2020).

[3] D. Rilastiyo Budi and Mp. Jurusan Penjas Fakultas Ilmu-Ilmu Kesehatan Universitas Jenderal Soedirman, "Evaluasi Pembelajaran Senam di Masa Pandemi Covid 19 Berbasis e-Learning Eldiru," 2021. Accessed: Mar. 05, 2021. [Online]. Available: https://osf.io/qtb46/.

[4] Y. Anistyasari, "STUDI LITERATUR EVALUASI DAN PEMERIKSAAN FITUR ALAT KUIS PADA LEARNING MANAGEMENT SYSTEM BERBASIS OPEN SOURCE,” Surabaya, Jan. 2020.

[5] E. Zacarias et al., "Optimizing the Access Records of Students in the Moodle Virtual Learning Environment Database,” IFAC-PapersOnLine, vol. 49, no. 30, 2016, doi: 10.1016/j.ifacol.2016.11.135.

[6] Rahayuning Putri Mahardikawati and Nurgiyatna, "SISTEM INFORMASI INDUSTRI KECIL MENENGAH PEMERINTAHAN KABUPATEN BOYOLALI BERBASIS WEBSITE,” Jurnal Teknik Informatika (Jutif), vol. 1, no. 2, 2020, doi: 10.20884/1.jutif.2020.1.2.13.

[7] M. M. Gultom and Maryam, "SISTEM INFORMASI PENJUALAN MATERIAL BANGUNAN PADA TOKO BANGUNAN BERKAH," Jurnal Teknik Informatika (Jutif), vol. 1, no. 2, 2020, doi: 10.20884/1.jutif.2020.1.2.19. 